\title{
MULTIFUNCTIONAL 3D MODEL FOR THE FARNESE THEATRE IN PARMA
}

\author{
A. Zerbi, S. Mikolajewska \\ Department of Engineering and Architecture, University of Parma, Parco Area delle Scienze, 181/a, 43124 Parma, Italy - \\ andrea.zerbi@unipr.it, sandra.mikolajewska@unipr.it
}

Commission II, WG II/8

KEY WORDS: Cultural Heritage, 3D Modeling, Integrated survey, NURBS, Farnese Theatre, Texture mapping, Video Mapping

\begin{abstract}
:
Modern surveying technologies allow to obtain a digital copy of cultural assets, which can be more or less adherent to reality. When $3 \mathrm{D}$ reconstruction concerns historical architecture, it is necessary to deal with a series of issues that may concern choosing of the most suitable survey methodologies, processing of acquired data, management of large amounts of data, making data always upgradable and easily editable, etc. By addressing these issues in advance and adopting an extremely interdisciplinary approach in the entire process, it is possible to identify the best methodologies to use in order to achieve a versatile 3D model.

This paper describes an ongoing research aimed at the creation of a multifunctional digital model of one of the most important 17 th century wooden theatres in Europe, the Farnese Theatre in Parma. The main aim is to generate a tool able to respond simultaneously to the different needs that have arisen in recent years, mostly related to the documentation, preservation, valorization and dissemination of knowledge about the monument. This article describes the project and the adopted methodology, focusing mainly on survey and modeling phases. Particular attention will also be paid to the process of reconstruction of the original decorations of the proscenium, completely lost after an Allied air raid in 1944. The illustrated methodologies define a possible workflow to be adapted in other similar contexts. Finally, possible uses of the generated model will be also briefly illustrated.
\end{abstract}

\section{INTRODUCTION}

One of the issues of $3 \mathrm{D}$ modeling in Cultural Heritage is the fact that a digital model might serve a multitude of purposes. Simple documentation in the broadest sense, support for historical studies (Aiello et al., 2020), building management (Fassi et al., 2015), planning of restoration and maintenance activities (Brumana et al., 2020) dissemination of knowledge (Denker, 2017; Banfi et al., 2020), enhancement support, are just some of the purposes a 3D model can cover. In this regard, answers can be quite diverse. The most common are: mesh models, NURBS (Non Uniform Rational Basis-Splines) models or parametric models. Depending on the type of modeling procedures adopted, defined according to the specific purposes of the research, the 3D model may be more or less adherent to reality.

The management of point clouds from LIDAR (Laser Imaging Detection and Ranging) and photogrammetric surveys of historic architectures, however, still presents some problems to be solved. As these artifacts are often complex and of considerable size, subject to deformations and irregularities, and characterized by heterogeneous and unique elements, their modeling still requires manual and time-consuming data processing. On the one hand, mesh and NURBS models are highly accurate in the generation of complex surfaces and allow to achieve a high degree of adherence to reality, but they cannot be used directly within BIM systems (Diara et al., 2019); on the other hand, in parametric models, each portion of the asset is simplified through objective and subjective operations (Adami et al., 2017).

In addition to defining the most appropriate methods for modeling a specific case study, it is equally important to validate the quality and accuracy of the model. Regarding this issue, the references are still poor (Garozzo et al., 2019). Since standardized procedures to validate this aspect are not yet defined, it is interesting to refer to the guide of the U.S. Institute for Building Documentation (USIBD, 2019). This document defines Level of Accuracy as a measurement result of the standard deviation between the point cloud and the model (Bonduel et al., 2017).

When the goal of the 3D model is to reconstruct heritage that no longer exists (both architectural and pictorial), the interpretation phase of the available sources becomes fundamental. In order to ensure scientific rigor to the philological reconstruction, it is necessary to make the whole process as transparent as possible (The London Charter, 2009).

If the possible applications of digital models of Cultural Heritage are increasingly numerous, at present, the biggest challenge is related to the creation of a model that is easily manageable and usable for different purposes.

One of the main aims of this ongoing research is to create an extremely versatile 3D model of the Farnese Theatre of Parma. Because of its characteristics, peculiarities, dimensions and complexity, the artifact represents an emblematic example of historical monument on which to deal with the issues related to this field of research.

\section{THE CASE STUDY}

\subsection{The Farnese Theatre in Parma}

The Farnese Theatre in Parma is one of the most important 17th century wooden theatres in Europe. Completed in 1619 by Ranuccio I Farnese and projected by Giovanni Battista Aleotti, the monument was almost completely destroyed during an Allied air raid in 1944. The damages suffered by the structure were devastating. Only a few elements survived: part of the 
proscenium, some structures leaning against the perimeter walls and the frescoes painted on them, protected by the loggias.

Starting from the 1950s, the theatre was reconstructed following a philological approach. The architectural structure was completely rebuilt, but not the sculptural apparatus and the decorations of the wooden elements, originally painted on all surfaces. Today it is possible to observe some traces of those decorations only in the parts that were reused during the reconstruction of the artifact.

The theatre (Figure 1), placed in a hall of about $33 \times 70$ meters approximately, has the same configuration of the post-war reconstruction. The monument is characterized by a U-shaped cavea sustained by a complex system of reticular beams. Above the bleachers there are two orders of loggias characterized by 17 Serlian windows on each level. The proscenium is surrounded by two triumphal arches placed on the side walls, which connect it with the bleachers. The roofing system of the hall is composed of 20 trusses able to cover a distance of 32 meters.

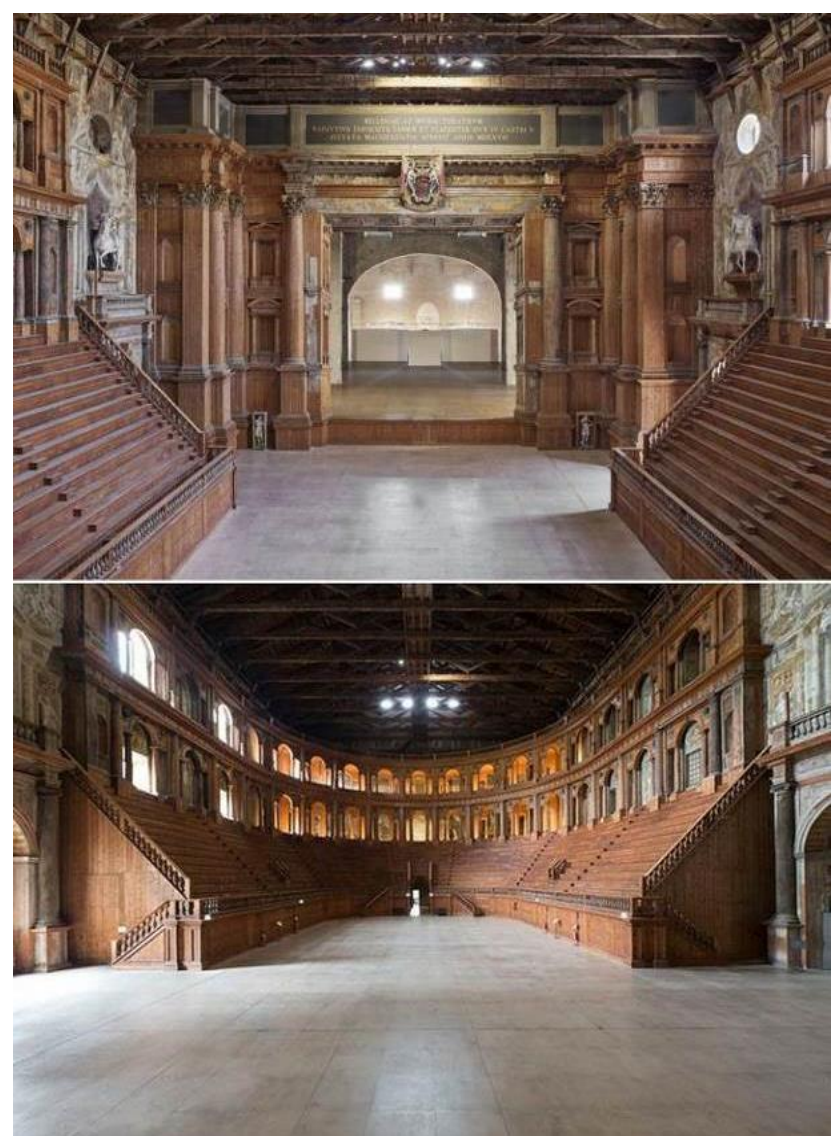

Figure 1. The Farnese Theatre in Parma (above: view of the proscenium, below: view of the bleachers).

\subsection{Methodological approach}

In order to create a versatile 3D model of such a complex structure, a specific workflow was followed, based on operations considered essential when dealing with historical monumental architectures.

The first phase involved knowledge acquisition on the case study, both from a historical and architectural standpoint. In order to document the wooden structures and the pictorial decorations inside the theatre, an accurate survey campaign of the structure was carried out. In the second phase, the acquired data were then processed by creating a $3 \mathrm{D}$ model of the monument. Particular attention was paid to the control and verification of its adherence to the surveyed data. The third phase concerned the digital reconstruction of the original decorations of the proscenium. As a result of the critical analysis and comparison of the many historical sources available, it was possible to proceed with the texturization of the model. The final phase of the research focused on examining the possible uses for the model. Among these, particular attention was paid to the development of a video mapping project aimed at the dissemination and communication of knowledge, the promotion of the use of Cultural Heritage, as well as the valorization of the monument.

From a methodological standpoint, the goal was to define a flexible workflow, possibly replicable in other similar contexts. In addition, from the beginning all activities were set up so that they were always upgradable. This choice results valid both for the execution of the survey and the creation of the model of the artifact that could be easily integrated in the future (for example in areas not documented at this phase of the research). Similar approach was adopted in the phase of texturization of the model. All operations carried out were set up to ensure easy transformation and integration of data. This choice is necessary when working on historical architecture, about which we rarely have completely exhaustive information.

\section{SURVEY CAMPAIGN}

The choice of the most suitable survey methods for the Farnese Theatre was based on the analysis of its geometric and material characteristics and was influenced by some logistics issues. Survey activities could only take place on the weekly public closing day. In order to ensure the highest possible degree of reliability of the measurements collected and to document the artifact of such considerable size, characterized by numerous complex elements and the presence of the pictorial apparatus on the perimeter walls of the hall, it was decided to use mainly indirect methods. They were used according to the best performance of the survey instruments.

First of all, it was decided to carry out a topographical survey of the structure. This had to serve as a reference for the subsequent measuring operations, based on TLS (Terrestrial Laser Scanning) and photogrammetric survey. The first was used for the geometric and dimensional definition of the entire structure, while the second was mainly aimed at documenting the frescoes.

\subsection{Topographic and laser scanner survey}

Since the measurement operations had to take place over several days, to the identification of station points and targets special attention was paid. The station points were placed in order that at least 3 different stations and at least 3 targets were visible from each point. In order not to reach too many stations, only the stations located under the bleachers were an exception to this approach.

In areas accessible to the public, station points were documented by choosing characteristic points, while in areas not accessible to the public, points were materialized on the ground. Six targets were also placed, in the least invasive locations possible.

The topographic survey, characterized by a closed network with ramifications, was performed with a Topcon Image Station IS2. For the survey of some points, the Leica ScanStation C10 laser scanner was used. This was possible because it can be used also as a topographical instrument.

As far as the laser scanner is concerned, a total of 35 scans with colorimetric data were carried out as follows: 6 scans at the 
floor level, 6 in the space under the bleachers, 2 on the stage, 9 at the level of the first loggia, 9 at the level of the second loggia and 3 at the cover level. Most of the scans were acquired with high resolution $(1$ point $/ 5 \mathrm{~cm}$ at $100 \mathrm{~m})$. Only in those points where the instrument was close to the structures of the theatre, and therefore would have had to measure points placed at a very short distance, scans with medium resolution were acquired $(1$ point $/ 10 \mathrm{~cm}$ at $100 \mathrm{~m}$ ).

Registration of the scans was done keeping as reference the point cloud coming from the topographic survey and was performed within the software Cyclone 9.2. As a final result, a single point cloud was obtained (Figure 2). This one, optimized in the post-processing phase, was used for the implementation of the 3D model of the theatre.

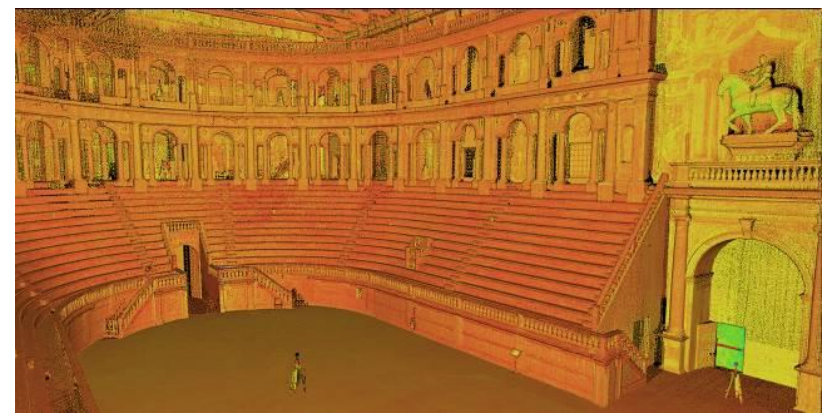

Figure 2. Point cloud from the laser scanner survey, after registration.

\subsection{Photogrammetric survey}

In parallel with the TLS survey, a photogrammetric survey of the pictorial apparatus was carried out. For the moment it was limited to the fresco placed on the back wall of the hall. This choice was linked to the fact of wanting to verify the relationship between the fresco and the architectural structure of the proscenium, always considered a specular copy of each other (Gandolfi, 1980).

Several issues were encountered during the photogrammetric campaign: the fresco is placed on a $32 \mathrm{~m}$ long wall and is divided into 7 areas not connected with each other because of the wooden structures leaning against the wall; the windows placed on the east wall of the hall and the spotlights pointing to the wooden structures generate strong contrasts between light and shadow on the decoration. The problems encountered led to considerable post-production work.

A Nikon D7200 with a resolution of $6000 \times 4000$ pixels and 24 $\mathrm{mm}$ optics (36 $\mathrm{mm}$ equivalent focal length) was used. All photographs were taken using the scheme with the optical axis of the camera as perpendicular to the wall as possible. In relation to the height of the fresco $(5.8 \mathrm{~m}$ at the level of the first loggia, $4.2 \mathrm{~m}$ at the level of the second loggia and $3.5 \mathrm{~m}$ at the last level), 1 to 3 stripes of photographs were necessary. Other detail shots were taken in the parts characterized by the high closeness of the wooden structures to the wall (for example near the stairs). Keeping an overlap between frames of at least $60 \%$, a total of about 360 photographs were acquired.

The data were processed within Agisoft Photoscan Professional 1.2.0 software. At first it was necessary to operate separately on the 7 parts of the fresco. Each portion of the decoration was processed with the following workflow: alignment of the frames, generation of the dense point cloud and its cleaning through the elimination of elements not strictly related to the wall (such as wooden structures).

The clouds thus generated were then used for the elaboration of DSM (Digital Surface Model) of the various parts of the fresco.
Finally, the 7 parts were correctly recomposed within the same reference system thanks to the coordinates surveyed by TLS survey. At the end, the high-resolution orthophoto of the entire decoration was produced (Figure 3).

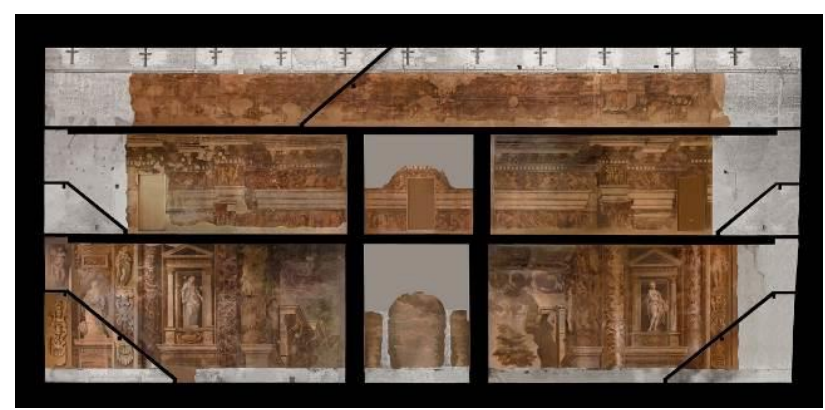

Figure 3. Orthophoto of the fresco placed on the back wall of the theatre.

\section{MODELING PHASE}

As it is well known, the field of modeling of Cultural Heritage, still faces some unsolved issues (Tommasi et al., 2016). Complex historical architectures such as the Farnese Theatre, in general are subject to deformation phenomena and are characterized by an extremely articulated plastic apparatus. So they are hardly suitable for parametric modeling, typically based on the use of standard and regular elements (Oreni et al., 2014). The complexity of these artifacts often makes them also unsuitable for a mesh modeling. Even if it allows to reach a high degree of detail, applied on such particular and unique objects, it would inevitably lead to management difficulties. An interesting solution is that of the free form modeling.

On the other hand, the field of modeling of historical Cultural Heritage is still characterized by the lack of common standards (Bruno et al., 2018). It is easy to understand how, according to the specific purposes of a model, it is possible to obtain different levels of adherence to reality.

Since it was necessary to create a model that could be used for very different purposes, the modeling phase of the Farnese Theatre was preceded by careful evaluation of the best procedures to adopt. The model had to coincide as much as possible with the survey data (according to the decisions taken as illustrated below), had to be used as a support to ordinary management operations, restoration, dissemination and communication of knowledge of the monument. To this aim it was decided to create a model composed by elements characterized by different levels of adherence to reality, obtained following slightly different procedures. In general, this approach is particularly suitable in the case of large and complex buildings, in which the subdivision of the digital model in several parts allows to optimize the management of the large amount of data (Fregonese et al., 2017).

As the fundamental goal was to find the correct balance between level of detail, time required for digital reconstruction and management of the model, 5 fundamental parts of the theatre were identified. These were selected according to their function within the structure and were denominated as "classes". The identified parts are: masonry perimeter walls, wooden elements characterizing the artifact (loggias, bleachers, proscenium), repetitive decorative elements, bleachers system and roofing system.

Considering the specific purposes of this research, it was decided not to proceed with the modelling of particularly complex plastic elements, such as the Farnese coat of arms, the equestrian statues and the medallions in relief on the loggias. 
However, when an ad hoc survey will be performed for each of these elements, it will be possible to integrate them within the general model of the theatre.

\subsection{Definition of the level of accuracy}

In order to establish the levels of adherence to the point cloud to be used in the modeling phase of the Farnese Theatre, it was decided to take an inspiration from the USIBD Level of Accuracy Specification Guide (USIBD 2019). In the guidelines, a classification of Levels of Accuracy (LOA) is proposed in terms of standard deviation (Table 1), determined by comparing different datasets or independent measurements. LOA have to be applied to each single element and not to the entire project, so within the same model there may be elements with different LOA, depending on how the element was surveyed and how it was modelled. The document also provides a subdivision of a building into different categories (such as Substructure, Shell, Interiors, etc.), easily recognizable in new buildings.

\begin{tabular}{|c|c|c|}
\hline Level & Upper range & Lower range \\
\hline LOA10 & Defined by user & $5 \mathrm{~cm}$ \\
\hline LOA20 & $5 \mathrm{~cm}$ & $1,5 \mathrm{~cm}$ \\
\hline LOA30 & $1,5 \mathrm{~cm}$ & $0,5 \mathrm{~cm}$ \\
\hline LOA40 & $0,5 \mathrm{~cm}$ & $0,1 \mathrm{~cm}$ \\
\hline LOA50 & $0,1 \mathrm{~cm}$ & 0 \\
\hline
\end{tabular}

Table 1. The LOA classification provided by USIBD.

Considering the size of the monument, which does not allow to achieve equal levels of accuracy for the entire structure, and the uniqueness of the elements that compose the artifact, it was decided to identify 5 different levels of adherence to reality for the classes of elements previously mentioned. For each level, the maximum value of the allowed standard deviation was established and the minimum value was always assumed to be 0 (the standard deviation value is obtained by comparing the point cloud with the 3D model) (Table 2). Since the standard deviation represents an average value, it means that in some points the deviation between the data can be even higher than the defined value. However, particular attention was paid to ensure that the punctual deviation between the data always remained within acceptable values and in any case not more than twice the maximum defined value.

\begin{tabular}{|c|c|c|}
\hline Level & Class & Max value \\
\hline Level 1 & Roofing system & Not defined \\
\hline Level 2 & Bleachers system & $10 \mathrm{~cm}$ \\
\hline Level 3 & Repetitive decorative elements & $4 \mathrm{~cm}$ \\
\hline Level 4 & $\begin{array}{c}\text { Wooden elements characterizing } \\
\text { the artifact }\end{array}$ & $1,5 \mathrm{~cm}$ \\
\hline Level 5 & Masonry perimeter walls & $0,5 \mathrm{~cm}$ \\
\hline
\end{tabular}

Table 2. Standard deviation levels adopted for the modeling of 5 classes of elements identified in the Farnese Theatre.

Level 5 was assigned to the masonry perimeter walls and level 4 was assigned to the wooden elements characterizing the artifact (loggias, bleachers, proscenium). In order to ensure the use of the model for the management and restoration of the monument, for these two parts of the theatre, it was chosen to maintain a high level of accuracy.
Level 3 was assigned to repetitive decorative elements. The maximum value of standard deviation equal to $4 \mathrm{~cm}$, can be apparently rather high for elements of not excessive dimensions. However, an absolutely faithful 3D reproduction of these would have required creating each component separately, which would be too time-consuming and would make the model too heavy. Level 2 was assigned to the category of bleacher support elements, while Level 1 was assigned to the roofing system. The choice of not repeating these last two classes with the highest level of adherence to reality is motivated by the fact that their faithful reproduction would have required an ad hoc survey and at the current state of this research was not its main goal.

\subsection{Modeling procedures}

For the processing of acquired data it was chosen to use a commercial free form modeling software, Rhinoceros 6.0. As previously mentioned, for each "class" of elements present within the theatre, it was adopted slightly different procedures. With the exception of operations performed on mesh surfaces, the procedures adopted still present a low level of automation. As far as masonry walls are concerned, it was decided to operate directly on the point cloud. This choice was motivated by the fact that the walls of the hall, like most of the historical structures, are characterized by numerous irregularities, imperfections, out of plumb, plaster blisters. In order to reconstruct them with a high level of adherence to reality, mesh surfaces were created. These were then subjected to optimization (filling holes, eliminating self-intersections and finishing edges) and decimation operations. With the aim to create easily manageable surfaces, it was necessary to decrease the number of tringles using different percentages of reduction (higher reduction percentages were adopted in the flat parts).

The wooden structures were created through NURBS surfaces. For the implementation of surfaces of this class, 3 different procedures were adopted: the extrusion of two-dimensional profiles along the related paths (flat surfaces, such as basement), the sliding of vertical sections along one or more paths (complex details, such as entablature), and the generation of surfaces from edge curves (non-planar surfaces, such as columns and half-columns).

For repetitive decorative elements (such as balusters or capitals) it was decided to reconstruct the regularized geometry of a typical element and to repeat it in a systematic way in every point where it was present. In order not to overload the model, a block was created for each element, which was copied several times. For the balusters (present in 3 versions for a total of 730 elements) revolution surfaces were created, obtained through the rotation of the vertical section profile around an axis of rotation. For the Ionic capitals at the level of the second loggia, a photogrammetric survey was carried out. The mesh model obtained was subsequently processed and transformed into a NURBS surface, which was placed in all 68 points where the capital is actually present. For the Corinthian capitals it was not possible to adopt the same methodology: because of their position it was not possible to carry out an accurate survey (capitals are not directly accessible to operators because they are in elevated positions). For this reason, starting from section curves obtained from the point cloud, two capitals were created (with circular and square plan), then copied and placed in the model.

For the bleachers system, composed of 56 beams (each of which is made of at least 7 elements properly interlocked and connected between them), it was chosen to accurately model one truss. Its modeling was based on the extrusion of twodimensional profiles along the related paths or by making the 
surfaces from edge curves. Each truss was repeated throughout the space below the bleachers, adapting the beam type to the variation of the length of the covered span.

It was chosen to reconstruct a typical truss in a regularized way for roofing system of the theatre too. To this aim, the already mentioned methodologies for the construction of NURBS surfaces were adopted.

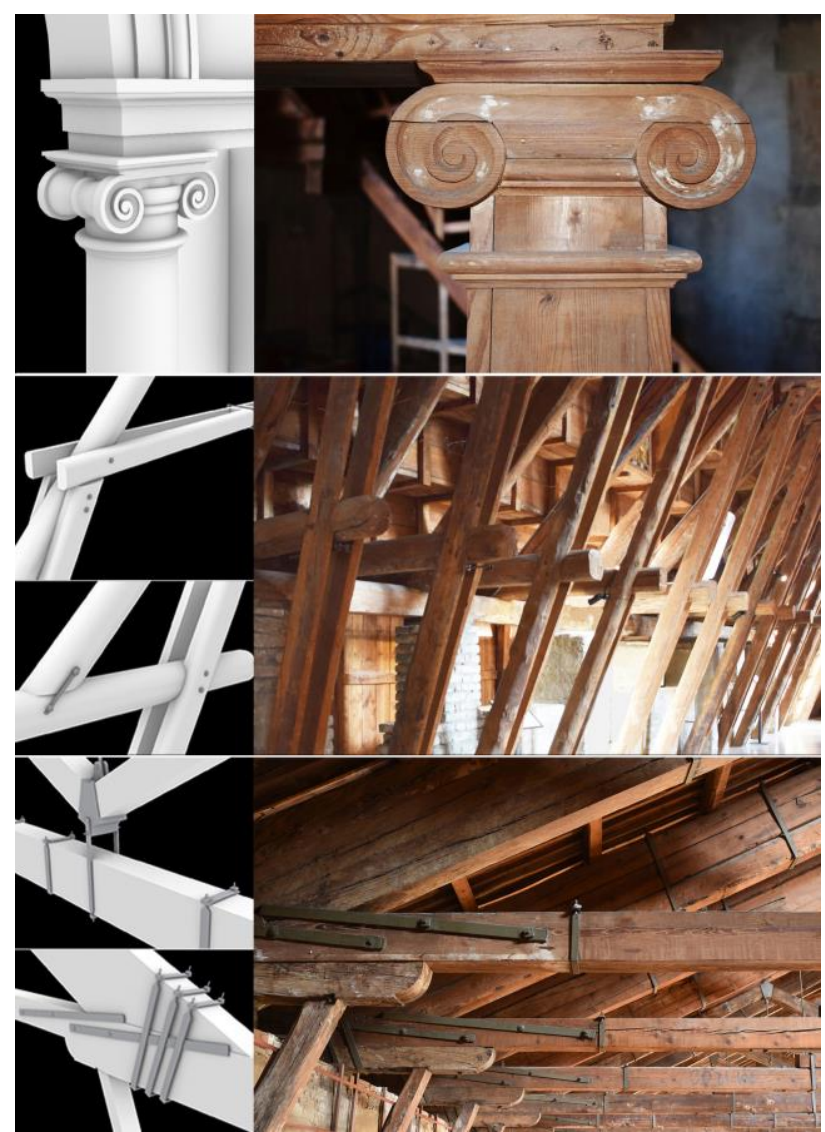

Figure 4. Photographs and digital reconstructions of some classes of elements present in the Farnese Theatre in Parma.

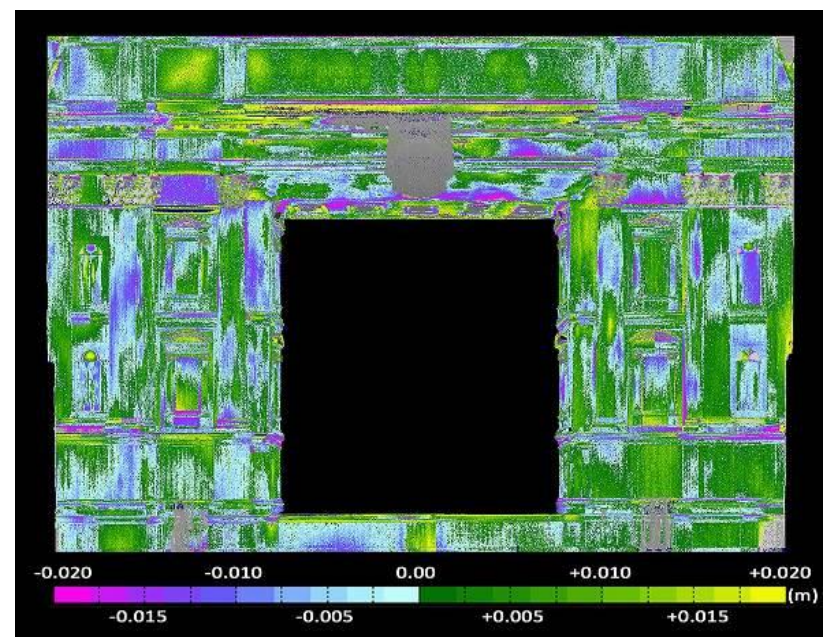

Figure 5. Comparison map (m) between the TLS point cloud and the 3D model of the proscenium.

In the modeling phase, the generated surfaces were continuously compared with the point cloud. This operation allowed to check and correct any discrepancies. The same comparison was also performed at the end of the modeling operations, in order to verify the correctness of the accuracy levels decided for the different classes of elements previously identified. For example, the comparison performed with Polyworks Inspector 10.0 software on the proscenium (Figure 5), showed a standard deviation value (StdDev) between the model and the point cloud equal to $0.00678 \mathrm{~m}$ (the model was considered without capitals so as not to falsify the data).

In order to optimize model management, the model itself was divided into several parts. The various units were then imported into the single file as an external reference.

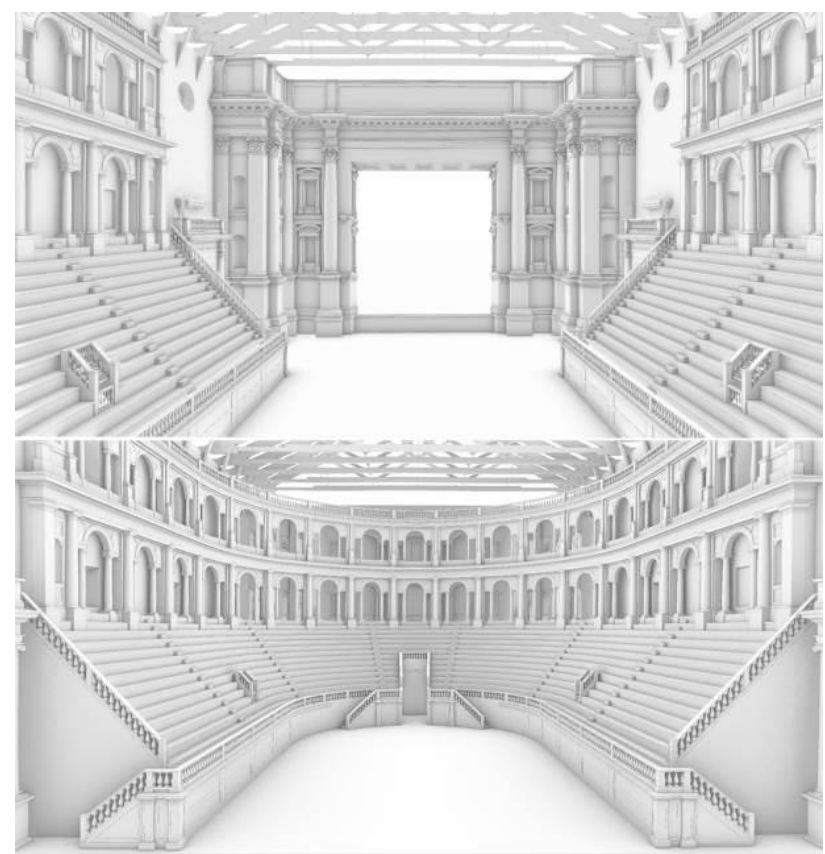

Figure 6. 3D model of the Farnese Theatre (above: view of the proscenium, below: view of the bleachers).

\subsection{From NURBS model into HBIM}

Since one of the possible uses of the digital model of the theatre is related to the management of the monument, it was decided to verify if the $3 \mathrm{D}$ model created could be easily modified and used also in a BIM environment. To test the validity of the procedure from a methodological standpoint, the experimentation was conducted on only part of the model. A portion of the bleachers was chosen (Figure 7), as it can be considered a significant part of the model.

For the processing of data, it was chosen to use a commercial software, Archicad 24. As a correct structuring of the model is essential in the BIM context, therefore, before importing the model in Archicad it was necessary to make some changes and integrations to the portion of the model interested by the experimentation. Those regarded mainly the definition of closed $3 \mathrm{D}$ geometries and the subdivision of some surfaces. The goal was to define a single, solid 3D entity for each element.

The numerous solids thus defined were then imported and placed in the Archicad Object Library. Each element was then classified according to the constructive principles of architecture (three-dimensional components of building were identified: Wall, Pillar, Beam, etc.).

Since BIM systems were developed mainly for the management of new constructions, the attributes that can be associated to the various elements are mainly related to the geometry and characteristics of materials. It is easy to understand that they are not sufficient for the complete description of a historical monument. 


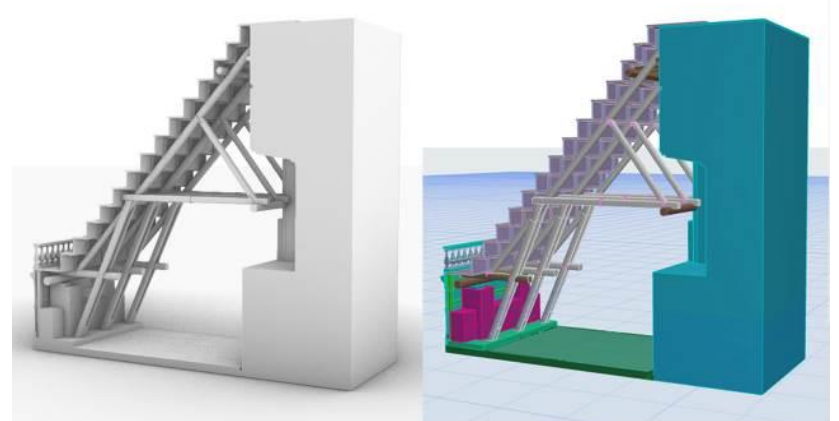

Figure 7. Part of the free form model of the bleachers transformed into a model that can be used directly on the BIM platform.

Considering that the unique elements that characterize the Farnese Theatre belong to an existing building and not a new one, it was considered useful to customize their attributes. The aim was to provide information that was functional to the management and conservation of the artifact. To this end, for each type of element it was necessary to identify new descriptive parameters.

For example, for the object defined as Beam, it was considered appropriate to indicate seven categories of attributes: general information (material, wood essence, dating, position), geometry of the elements (height, width, length, volume, section type, end cutting angle), mechanical characteristics (related to the resistance of the material), presence of connections (bolts, bands, brackets and their number), state of conservation (presence of deformations, cracks, nodes), history of interventions carried out.

It was considered of fundamental importance the addition of a link to the photographic documentation of the elements, to the available structural reports and to the survey data (in this case formed by the point clouds and by the two-dimensional survey drawings).

The categories of attributes chosen represent only one of the many possibilities. For the moment, it was added information considered essential for the planned conservation of the monument. In the future, both the categories and the subcategories can be enriched by more levels of information.

\subsection{Texture mapping}

In origin, the entire Farnese Theatre was covered by a very rich pictorial decoration. Today, it can be admired only in the precious photographs that documents the state of the artifact before the bombings of 1944 (Figure 8). If performed philologically, digital reconstruction of the original decoration of the structure represents an extraordinary tool for the dissemination and communication of knowledge (Giovannini 2020). In this context, particular importance has the accurate model of the theatre previously created.

At the present state of research, the reconstruction of the decoration was limited to the proscenium area. It represents one of the most documented parts of the theatre. This operation was based primarily on the critical analysis and continuous comparison of 3 types of sources: written sources (description of the inaugural spectacle of 1628 by M. Buttigli in which the entire theatre is described in detail), materials sources (19th century model of the opera attributed to Fanti and Rousseau; fresco located on the back wall of the hall), and visual sources (historical drawings of the theatre, pictorial representations and photographs).

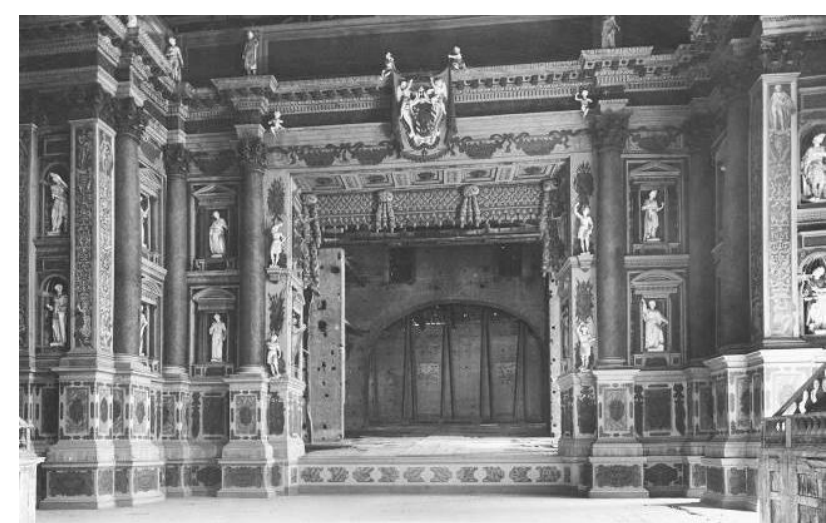

Figure 8. Farnese Theatre before the 1944 destruction. Photography from Alinari collection.

From a methodological standpoint, the reconstruction of the decoration was organized in two phases. The first phase concerned the identification of the elements from a figurative point of view, the second one was dedicated to the identification of their colors. Since all the photos taken before the destruction of the artwork were in black and white, this last step represented one of the most critical phases of the entire process.

Once the identification phase of the numerous elements that originally characterized the proscenium was completed, it was possible to proceed with the digital elaboration of the decorations. The two-dimensional images in raster format were created and used to mapping the $3 \mathrm{D}$ model. Some of these were generated using the orthophoto of the decoration placed on the back wall of the hall. For the digital reconstruction of the decorations it was used Adobe Photoshop CC 2017 postproduction software. More than 200 images were generated with a resolution of $300 \mathrm{dpi}$ and an average weight of about 1 MB.

The process of identification and reconstruction of the numerous elements of the decoration is not the aim of this paper, whereas the application of the images on the 3D model is. This operation was carried out within the same software used in the modeling phase, Rhinoceros 6.0 (Figure 9).

In the first phase, starting from the previously prepared images, more than 200 different "materials" were created and placed in the Material Library. Three different operating procedures were used for their mapping on the 3D model. The first procedure involved the creation of a planar mapping and involved all the flat faces of the model, for which ad hoc images were created (pedestals, niches, pilasters, friezes). The second procedure was based on custom mapping and concerned complex surfaces (moldings). In this case it was necessary to edit the UV mapping of the texture. The last procedure involved parts of the proscenium, which were painted in a fashion that simulated precious materials and concerned all the surfaces of the model not involved in the operations previously illustrated. In relation to the surface involved, the scale parameters of the 3 materials most present in the proscenium (gold, marble and porphyry) were modified.

In order to ensure an easy future transformation and integration of materials, specific solutions were adopted. First of all, the images used for the textures were generated starting from files in which the various levels of regulation are separated. In addition, the link of materials to raster files is always active. In this way, when it becomes necessary to modify any decoration, it will be sufficient to transform the image used for the definition of the relative texture. The 3D model will update itself in a completely automatic way. 


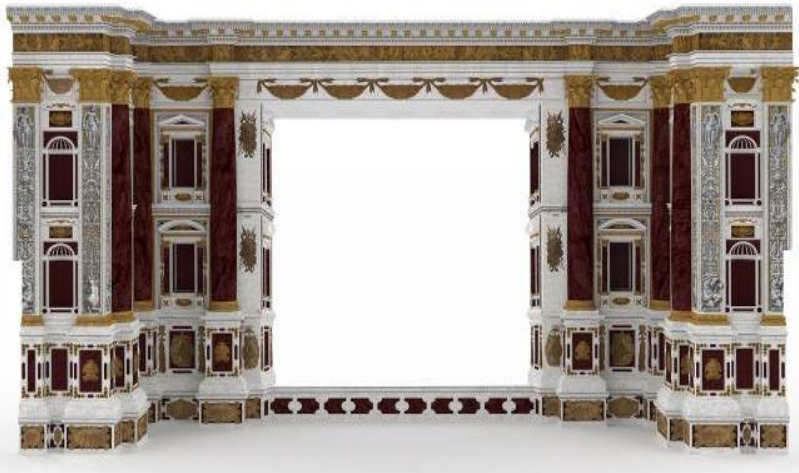

Figure 9. Textured model with reconstruction of the original decoration of the proscenium.

\section{USES OF THE FARNESE THEATRE MODEL}

The 3D model created from the beginning with the intent to make it extremely versatile, is in fact characterized by numerous areas of application.

First of all, the generated model has allowed to accurately document the monument which, at present, lacks reliable surveys, not even the traditional 2D drawings (plans and sections). The possibility of extrapolating detailed drawings from the model, in any point of the structure and at any time, represents a significant advantage for those who manage the monument.

The 3D model is also an important support tool for study activities. Starting from the survey drawings obtained from the model, compared with some historical representations dating before the 1944 destruction of the artifact, it was possible to verify some issues related to the accuracy of the twentiethcentury reconstruction of the monument. It was also possible to carry out a first metric analysis of the relationship between the fresco painted on the back wall and the wooden proscenium (Mikolajewska et al., 2019). For this purpose, the digital model of the fresco and that of the proscenium were projected onto a vertical plane placed between the two (they are placed on two planes about 50 meters apart, almost perfectly parallel to each other). In doing so, the two models were overlapped and mirrored against each other (Figure 10).

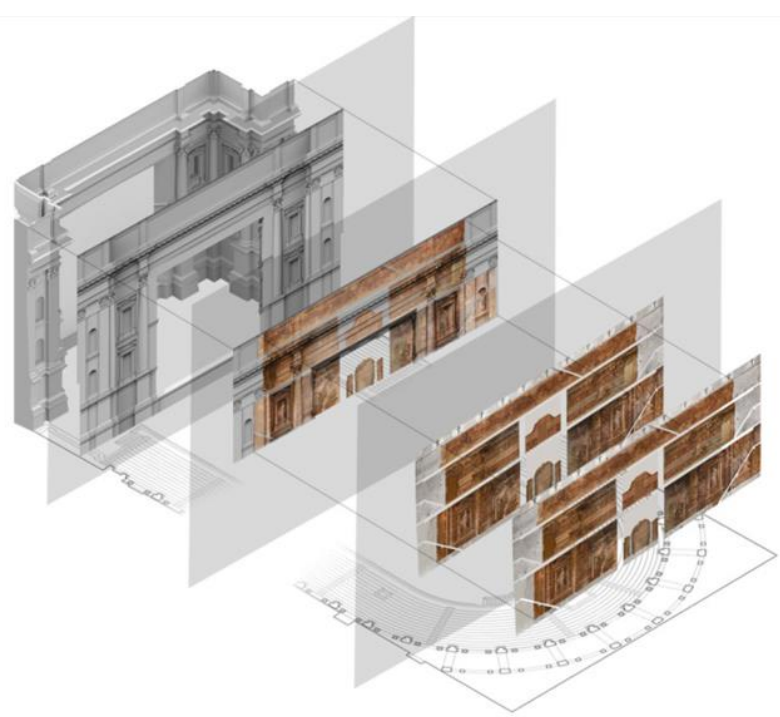

Figure 10. Projection of the 3D model of the proscenium and the mesh model of the fresco on the same reference plane.
The overlapping showed a surprising coincidence between the fresco and the proscenium. Despite some deviations recorded of the maximum order of about $20 \mathrm{~cm}$ (justified also in relation to the restorations activities undergone by both structures and the distance that separates them), it cannot be denied that the two are a mirror copy of each other.

As already illustrated in the previous paragraphs, the generated 3D model can be used for the conservation and management of the monument within BIM systems. This requires only a few and easy transformations of some elements of the model.

The model can be also used for the dissemination and communication of knowledge about the monument. The digital reconstruction of the original decoration of the proscenium, in fact, represents a useful tool for the creation of didactic material aimed at the dissemination of scientific and cultural content. This type of material can be used both in site and online.

The textured model of the proscenium is also a fundamental tool for the visualization of the original decoration on the wooden structure. This goal can be achieved using a particular form of augmented reality, commonly known as the technique of video mapping. In fact, on the basis of the accurate model of the structure it was possible to develop a project aimed to projection of the decorations on the structure. Due to the ongoing pandemic situation, the project has not yet been set up.

\section{CONCLUSIONS}

The research conducted on the Farnese Theatre in Parma has highlighted the importance of adopting an integrated approach in the specific context of historical architecture, both in the survey and data processing phases. In particular, this paper discusses the application of different modeling procedures (based on NURBS and mesh surfaces) to the creation of a versatile $3 \mathrm{D}$ model.

In general, free form modeling allows to achieve a high degree of detail. In the digital reconstruction of complex architectures, almost always characterized by many unique and unrepeatable elements, this aspect is particularly significant. For the management of a great amount of data that inevitably is generated in these cases, the correct organization of the $3 \mathrm{D}$ model is fundamental. The division of the architecture into different categories of elements, to be reconstructed digitally with different levels of accuracy, may represent a possible solution for the creation of a multifunctional 3D model easily manageable and potentially usable in different research areas.

The proposed methodology adopted in the modeling phase can be easily replicated in other cases. The same consideration is valid also for the methodology adopted for the texturization of the model. In the field of historical monumental architectures, it is considered of extreme importance to operate from the beginning with the purpose of always making upgradable and easily modifiable what is being created. It is important to leave the possibility of integration of data from any further useful sources.

In addition to the applications described in this paper, the 3D model of the Farnese Theatre can be used in many other areas of research. To mention two, the dissemination of knowledge through open access databases and the promotion of alternative uses of Cultural Heritage. For this latter purpose, it is possible to print the generated model or use it within virtual reality systems.

Regardless of the uses that the 3D model may have, it is necessary to stress that scientifically correct digital reconstruction represents the first step in the protection, preservation and valorization of the monument. 


\section{REFERENCES}

Adami, A., Scala, B., Spezzoni, A., 2017. Modelling and accuracy in a BIM environment for planned conservation: the apartment of Troia of Giulio Romano. Int. Arch. Photogramm. Remote Sens. Spatial Inf. Sci., XLII-2/W3, 17-22. 10.5194/isprs-archives-XLII-2-W3-17-2017.

Adobe Photoshop - https://www.adobe.com/it/products/ photoshop.html - Accessed 03/2021.

Aiello, D., Bolognesi, C., 2020. Reliving history: the digital reconstruction of the convent of Santa Maria delle Grazie in Milan. Virtual Archaeology Review, 11(23): 106-126. doi.org/10.4995/var.2020.13706.

Archicad - https://graphisoft.com/it - Accessed 03/2021.

Banfi, F., Oreni, D., Bonini, J.A., 2020. The Arch of Peace of Milan and its Historic Memory: from 3D Survey and HBIM to Mixed Reality (VR-AR), in Arena, A., Arena, M., Brandolino, R.G., Colistra, D., Ginex, G., Mediati, D., Nucifora, S., Raffa, P. (edited by), Connecting. Drawing for weaving relationships, Atti del $42^{\circ}$ Convegno Internazionale dei Docenti della Rappresentazione, FrancoAngeli OpenAccess, Milan, pp. 16691677.

Bonduel, M., Bassier, M., Vergauwen, M., Pauwels, P., Klein, R., 2017. Scan-to-BIM output validation: towards standardized geometric quality assessment of Building Information Models based on point clouds. Int. Arch. Photogramm. Remote Sens. Spatial Inf. Sci., XLII-2/W8, 45-52. doi.org/10.5194/isprsarchives-xlii-2-w8-45-2017.

Brumana, R., Oreni, D., Barazzetti, L., Cuca, B., Previtali, M., Banfi, F., (2020) Survey and Scan to BIM Model for the Knowledge of Built Heritage and the Management of Conservation Activities. In: Daniotti B., Gianinetto M., Della Torre S. (eds) Digital Transformation of the Design, Construction and Management Processes of the Built Environment. Research for Development. Springer, Cham. https://doi.org/10.1007/978-3-030-33570-0_35.

Bruno, N., Roncella, R., 2018. A restoration oriented HBIM system for Cultural Heritage documentation: the case study of Parma Cathedral. Int. Arch. Photogramm. Remote Sens. Spatial Inf. Sci., XLII-2/WG II/8, 171-178. doi.org/10.5194/isprsarchives-XLII-2-171-2018.

Denker, A., 2017. Rebuilding Palmyra virtually: recreation of its former glory un digital space. Virtual Archaeology Review, 8(17): 20-30. doi.org/10.4995/var.2017.5963.

Diara, F., Rinaudo, F., 2019. From reality to parametric models of Cultural Heritage assets for HBIM. Int. Arch. Photogramm. Remote Sens. Spatial Inf. Sci., XLII-2/W15, 413-419. doi.org/10.5194/isprs-archives-XLII-2-W15-413-2019.

Fassi., F., Achille, C., Mandelli, A., Rechichi, F., Parri, S., 2015. A new idea of BIM system for visualization, web sharing and using huge complex 3D models for facility management. Int. Arch. Photogramm. Remote Sens. Spatial Inf. Sci., XL5/W4, 359-366. doi.org/10.5194/isprsarchives-XL-5-W4-3592015 .
Fregonese, L., Taffurelli, L., Adami, A., Chiarini, S., Cremonesi, S., Helder, J., Spezzoni, A., 2017. Survey and modelling for the BIM of Basilica of San Marco in Venice. Int. Arch. Photogramm. Remote Sens. Spatial Inf. Sci., XLII-2/W3, 303-310. doi.org/10.5194/isprs-archives-XLII-2-W3-303-2017.

Gandolfi, V., 1980: Il Teatro Farnese di Parma. Luigi Battei, Parma.

Garozzo, R., Lo Turco, M., Santagati, C., 2019.Information Models to Manage Complexity for an Integrated Knowledge Project. Diségno, 4/2019: 225-236.

doi.org/10.26375/disegno.4.2019.21.

Giovannini, E. C., 2020. Workflow for an evidence-based virtual reconstruction: the marbles of the ciborium of the early medieval Monte Sorbo Church. Int. Arch. Photogramm. Remote Sens. Spatial Inf. Sci., XLIII-B2-2020, 1395-1402. doi.org/10.5194/isprs-archives-XLIII-B2-2020-1395-2020.

Mikolajewska, S., Zerbi, A., 2019. Uno specchio dell'arte: il proscenio e l'affresco sulla parete di fondo del teatro Farnese di Parma, in Belardi, P. (edited by), Riflessioni. L'arte del disegno e disegno dell'arte, Atti del $41^{\circ}$ Convegno Internazionale dei Docenti della Rappresentazione (Perugia, 19-21 settembre 2019), Gangemi Editore, Roma, pp. 1027-1034.

Oreni, D., Brumana, R., Banfi, F., Bertola, L., Barazzetti, L., Cuca, B., Previtali, M., Roncoroni, F., 2014. Beyond Crude 3D Models: From Point Clouds to Historical Building Information Modeling via NURBS. Lecture Notes in Computer Science, vol. 8740. Springer, Cham. doi.org/10.1007/978-3-319-13695-0_16.

Polyworks Inspector - https://www.innovmetric.com/it/ products/polyworks-inspector - Accessed 03/2021.

Rhinoceros - https://www.rhino3d.com/it/ - Accessed 03/2021.

The London Charter for the Computer-based Visualisation of Cultural Heritage, 2009 - http://www.londoncharter.org/ downloads.html - Accessed 03/2021.

Tommasi, C., Achille, C., Fassi, F., 2016. From point cloud to BIM: a modelling challenge in the Cultural Heritage field. Int. Arch. Photogramm. Remote Sens. Spatial Inf. Sci., XLI-B5, 429-436. doi.org/10.5194/isprs-archives-XLI-B5-429-2016.

USIBD Level of Accuracy (LOA) Specification Guide, 2019, v 3.0-2019. 